\section{Case Reports in Neurology}

Case Rep Neurol 2021;13:17-23

DOI: 10.1159/000511026
Published online: January 21, 2021

(C) 2021 The Author(s)

www.karger.com/crn

This article is licensed under the Creative Commons Attribution-NonCommercial 4.0 International License (CC BY-NC) (http://www.karger.com/Services/OpenAccessLicense).

Usage and distribution for commercial purposes requires written permission.

\title{
Anti-N-Methyl-D-Aspartate Receptor Encephalitis with Decrease in Blood Flow in Cerebellum
}

\author{
Koji Obara Tomoko Ono Itaru Toyoshima \\ Department of Neurology, National Hospital Organization, Akita National Hospital, \\ Yurihonjo, Japan
}

\section{Keywords}

Cerebellum $\cdot$ Encephalitis $\cdot$ Methotrexate $\cdot \mathrm{N}$-methyl-D-aspartate receptor $\cdot$ SPECT

\begin{abstract}
In anti-N-methyl-D-aspartate receptor (NMDAR) encephalitis, progressive cerebellar atrophy potentially leads to severe sequelae. We encountered a patient with anti-NMDAR antibody encephalitis who showed a decrease of blood flow in the cerebellum. A 15-year-old girl presented with consciousness disturbance. Influenza encephalopathy was suspected, and she was treated with glucocorticoid pulse therapy, high-dose intravenous immunoglobulins, and plasma exchange sequentially. She subsequently underwent left oophorectomy due to the presence of anti-NMDAR antibodies and a left ovarian teratoma. In spite of the surgery, her neuropsychiatric symptoms persisted, and she recovered slowly after the introduction of oral methotrexate (MTX). Sequential cerebral blood flow monitoring with single-photon emission computed tomography showed marked cerebellar hypoperfusion. Although mild impairments including working memory and verbal fluency persisted, she eventually returned to high school 3 years after onset. Profound cerebellar hypoperfusion including lobules VI and VII may be the reason for her working memory impairment and speaking problems. Oral MTX may be a promising alternative treatment for some refractory cases of anti-NMDAR encephalitis.
\end{abstract}

(C) 2021 The Author(s)

Published by S. Karger AG, Basel 


\section{Case Reports in Neurology}

Case Rep Neurol 2021;13:17-23

\begin{tabular}{l|l}
\hline DOI: $10.1159 / 000511026$ & (c) 2021 The Author(s). Published by S. Karger AG, Basel
\end{tabular} www.karger.com/crn

Obara et al.: Anti-NMDAR Encephalitis with Cerebellar Hypoperfusion

\section{Introduction}

Anti-N-methyl-D-aspartate receptor (NMDAR) encephalitis is the most common antineuronal antibody encephalitis among the autoimmune types of encephalitis found at present. Progressive cerebellar atrophy potentially develops in patients with severe disabilities due to anti-NMDAR encephalitis [1,2]. Here, we report a patient with anti-NMDAR antibody encephalitis who showed a persistent decrease of blood flow in the cerebellum with slight cerebellar atrophy. The patient did not respond to first- and second-line treatments, but slowly recovered after oral administration of oral methotrexate (MTX), resulting in a good outcome. The patient presented with mild working memory impairment and speaking problems as sequelae. We were able to detect the cerebellar involvement associated with these sequelae by sequential cerebral blood flow single-photon emission computed tomography (SPECT).

\section{Case Report/Case Presentation}

We described the clinical course of this case in Figure 1. A 15-year-old girl who was previously healthy had a headache with a high fever. She presented with consciousness disturbance 3 days later and was admitted, at which time she was found to be positive for influenza A virus infection based on nasal smear. Magnetic resonance imaging (MRI) did not reveal any abnormalities in the brain. Cerebrospinal fluid (CSF) study disclosed lymphocytic pleocytosis with 166 leukocytes $/ \mathrm{mm}^{3}$ including 72\% lymphocytes and increased total protein $1.1 \mathrm{~g} / \mathrm{L}$ (normal $<0.5 \mathrm{~g} / \mathrm{L}$ ). Influenza encephalopathy was suspected, and she was started on glucocorticoid pulse therapy, high-dose intravenous immunoglobulins (IVIG), and plasma exchange (PE) sequentially. Because of development of status epilepticus, she was mechanically ventilated with tracheostomy. Since the presence of anti-NMDAR antibodies in CSF and a left ovarian teratoma on MRI were subsequently found, she underwent left oophorectomy 90 days after onset. Additionally, she received cyclophosphamide pulse therapy. Although her status epilepticus subsided, she remained unconscious. She was transferred to our hospital 7 months after onset. On neurological examination, she opened her eyes occasionally, but she was unresponsive to external stimuli. All brainstem reflexes were preserved. She showed involuntary movements such as risus caninus and rotation of the right foot. Muscle tone in all four limbs was decreased. Babinski signs were negative on both feet. She showed marked salivation and sweating. Brain MRI showed atrophy of the hippocampus and dilation of the lateral and third ventricles (Fig. 2a), and slight cerebellar atrophy (Fig. 2b). SPECT using N-isopropyl-p-[123I] iodoamphetamine showed a blood flow decrease in the bilateral frontal lobes with slight hypoperfusion in the right anteromedial portion of the cerebellum (Fig. 3a). She was weaned off the ventilator 11 months after onset. However, her involuntary movements extended to the whole body and became ballistic. She remained mute without eye contact. In the follow-up CSF tests using a commercially available cell-based assay kit (EUROIMMUN, Lubeck, Germany), anti-NMDAR antibodies remained positive. She was started on MTX 6 mg per week via gastrectomy, following oral administration. She began to stare at people and watch television 15 months after onset but was often agitated and resisted medical care. Seventeen months after onset, she became able to communicate in writing and whispering, which was an echolalia at first and later conversation with short sentences. Additionally, she was able to walk without any assistance. She completed the Wechsler Adult Intelligence Scale-Fourth Edition (WAIS-IV) 19 months after onset, showing full scale IQ 56 without a significant difference

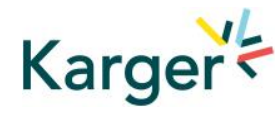




\section{Case Reports in Neurology}

Case Rep Neurol 2021;13:17-23

\begin{tabular}{l|l}
\hline DOI: $10.1159 / 000511026$ & (c) 2021 The Author(s). Published by S. Karger AG, Basel
\end{tabular} www.karger.com/crn

Obara et al.: Anti-NMDAR Encephalitis with Cerebellar Hypoperfusion

between each index scale. She was discharged and followed up in our hospital outpatient clinic. Twenty-four months after onset, she had difficulty memorizing what she heard, but she began to study elementary school subjects, and later she could study more advanced material. Her speech gradually became more natural, but stuttering and cluttering ultimately remained. On SPECT, hypoperfusion in the frontal lobe disappeared, while hypoperfusion of the cerebellum was more marked and extended bilaterally with right posterior side predominance (Fig. $3 b)$. However, at that time, she did not show any motor complications based on cerebellar involvement. The CSF test was still positive for anti-NMDAR antibodies with a titer of 1: 20. However, MTX was stopped. On neuropsychological testing 34 months after onset, the MiniMental State Examination score and the Frontal Assessment Battery were 30/30 points and $17 / 18$ points, respectively. On WAIS-IV, she showed improvement in full-scale IQ and all index scales, but the working memory index was still low. Thirty-six months after onset, antiNMDAR antibodies in CSF remained positive with the titer decreasing to 1: 1, and SPECT still showed hypoperfusion of the cerebellum (Fig. 3c). On brain MRI, slight cerebellar atrophy was unchanged, while reversal of cerebral atrophy was found (Fig. 2c). She ultimately returned to high school.

\section{Discussion/Conclusion}

We found two important clinical implications, i.e. the patient showed a persistent decrease in blood flow in the cerebellum and her symptoms improved after oral administration of MTX.

It is reported that cerebellar atrophy on MRI is irreversible and associated with a poor outcome in anti-NMDAR encephalitis [1,2]. Certainly, although slight cerebellar atrophy on MRI found during her course was irreversible, she did not present with any motor disabilities based on cerebellar involvement and subsequently had a good outcome. However, she presented with mild sequelae including working memory impairment and speaking problems such as stuttering and cluttering. Recently, increasing evidence has demonstrated that the cerebellum contributes to non-motor functions such as emotion, language, and working memory [3-8]. The regions within the cerebellum responsible for these non-motor functions are identified by functional MRI and positron emission tomography studies.

Working memory uses attention to manipulate information that is immediately available to execute cognitive tasks, and activates bilateral cerebellar regions including lobules VI and VII (crus I) [3-7]. The damage to these areas causes working memory impairments including arithmetic, digit span, verbal comprehension, and story recall, which are strongly related to learning ability [3-7].

Non-motor and higher-level language function within the cerebellum is associated with word generation and verbal fluency. Language tasks activate predominantly right-hemisphere regions in lobules VI and VII $[3,4]$. The damage to these lobules causes decreased word production and verbal disfluency $[7,8]$.

In our patient, SPECT performed 24 and 36 months after onset showed bilateral cerebellar hypoperfusion with a right-side predominance including lobules VI and VII. Taken together, we considered that the findings on SPECT reflect her working memory impairment and speaking problems.

The second clinical implication in this case is that her symptoms improved after oral administration of MTX. At the acute stage, she was treated with first-line (glucocorticoid, IVIG,

\section{Karger'=}




\section{Case Reports in Neurology}

\begin{tabular}{|c|c|}
\hline \multicolumn{2}{|c|}{ Case Rep Neurol 2021;13:17-23 } \\
\hline DOI: 10.1159/000511026 & $\begin{array}{l}\text { (c) } 2021 \text { The Author(s). Published by S. Karger AG, Basel } \\
\text { www.karger.com/crn }\end{array}$ \\
\hline
\end{tabular}

and PE) and second-line treatments (cyclophosphamide) for anti-NMDAR encephalitis [9-11]. However, because she did not respond to these treatments and anti-NMDAR antibodies in CSF remained positive, we started oral administration of MTX. Although the effectiveness of MTX for anti-NMDAR encephalitis has been reported with intrathecal administration [12], we chose oral administration because of the difficulty of intrathecal administration due to her psychomotor agitation. Despite persistent anti-NMDAR antibodies in CSF, sufficient neurological improvement was achieved, so administration of MTX was discontinued 2 years after onset [11]. After that, she continued to recover slowly. Oral MTX should be considered as an additional option for anti-NMDAR encephalitis because of its ease of administration and safety.

In conclusion, our patient showed a decrease in blood flow in the cerebellum during longterm observation. We consider SPECT and neuropsychological tests to be important to detect mild cognitive sequelae in patients recovering from anti-NMDAR encephalitis. Her symptoms improved after oral administration of MTX. We suggest that oral MTX may be a promising alternative treatment for cases with anti-NMDAR encephalitis that do not respond to first-line and second-line treatments. Further data should be gathered regarding the effectiveness of oral administration of MTX for anti-NMDAR encephalitis.

\section{Statement of Ethics}

The parents of the patient provided both oral and written informed consent for the publishing of this report (including publication of images).

\section{Conflict of Interest Statement}

The authors have no conflicts of interest to declare.

\section{Funding Sources}

The authors did not receive any external funding.

\section{Author Contributions}

Koji Obara was the patient's primary neurologist and drafted the manuscript. Tomoko Ono performed the neuropsychological testing of the patient. Itaru Toyoshima revised the manuscript and edited the paper.

\section{References}

1 Iizuka T, Kaneko J, Tominaga N, Someko H, Nakamura M, Ishima D, et al. Association of Progressive Cerebellar Atrophy With Long-term Outcome in Patients With Anti-N-Methyl-d-Aspartate Receptor Encephalitis. JAMA Neurol. 2016 Jun;73(6):706-13.

2 Huang Q, Xie Y, Hu Z, Tang X. Anti-N-methyl-D-aspartate receptor encephalitis: A review of pathogenic mechanisms, treatment, prognosis. Brain Res. 2020 Jan;1727:146549.

\section{Karger'=}




\section{Case Reports in Neurology}

\begin{tabular}{l|l}
\hline Case Rep Neurol 2021;13:17-23 \\
\hline DOI: 10.1159/000511026 & $\begin{array}{l}\text { (c) } 2021 \text { The Author(s). Published by S. Karger AG, Basel } \\
\text { www.karger.com/crn }\end{array}$ \\
\hline Obara et al.: Anti-NMDAR Encephalitis with Cerebellar Hypoperfusion
\end{tabular}

3 Stoodley CJ, Schmahmann JD. Functional topography in the human cerebellum: a meta-analysis of neuroimaging studies. Neuroimage. 2009 Jan;44(2):489-501.

4 Stoodley CJ, Valera EM, Schmahmann JD. Functional topography of the cerebellum for motor and cognitive tasks: an fMRI study. Neuroimage. 2012 Jan;59(2):1560-70.

5 Argyropoulos GP, van Dun K, Adamaszek M, Leggio M, Manto M, Masciullo M, et al. The Cerebellar Cognitive Affective/Schmahmann Syndrome: a Task Force Paper. Cerebellum. 2020 Feb;19(1):102-25.

6 e KH, Chen SH, Ho MH, Desmond JE; E KH. A meta-analysis of cerebellar contributions to higher cognition from PET and fMRI studies. Hum Brain Mapp. 2014 Feb;35(2):593-615.

7 Seese RR. Working Memory Impairments in Cerebellar Disorders of Childhood. Pediatr Neurol. 2020 Jun;107:16-23.

8 Schweizer TA, Alexander MP, Susan Gillingham BA, Cusimano M, Stuss DT. Lateralized cerebellar contributions to word generation: a phonemic and semantic fluency study. Behav Neurol. 2010;23(1-2):317.

9 Dalmau J, Graus F. Antibody-Mediated Encephalitis. N Engl J Med. 2018 Mar;378(9):840-51.

10 Wang H, Xiao Z. Current Progress on Assessing the Prognosis for Anti-N-Methyl-D-Aspartate Receptor (NMDAR) Encephalitis. BioMed Res Int. 2020 Apr;2020:7506590.

11 Dalmau J, Armangué T, Planagumà J, Radosevic M, Mannara F, Leypoldt F, et al. An update on anti-NMDA receptor encephalitis for neurologists and psychiatrists: mechanisms and models. Lancet Neurol. 2019 Nov;18(11):1045-57.

12 Tatencloux S, Chretien P, Rogemond V, Honnorat J, Tardieu M, Deiva K. Intrathecal treatment of anti-NMethyl-D-aspartate receptor encephalitis in children. Dev Med Child Neurol. 2015 Jan;57(1):95-9.

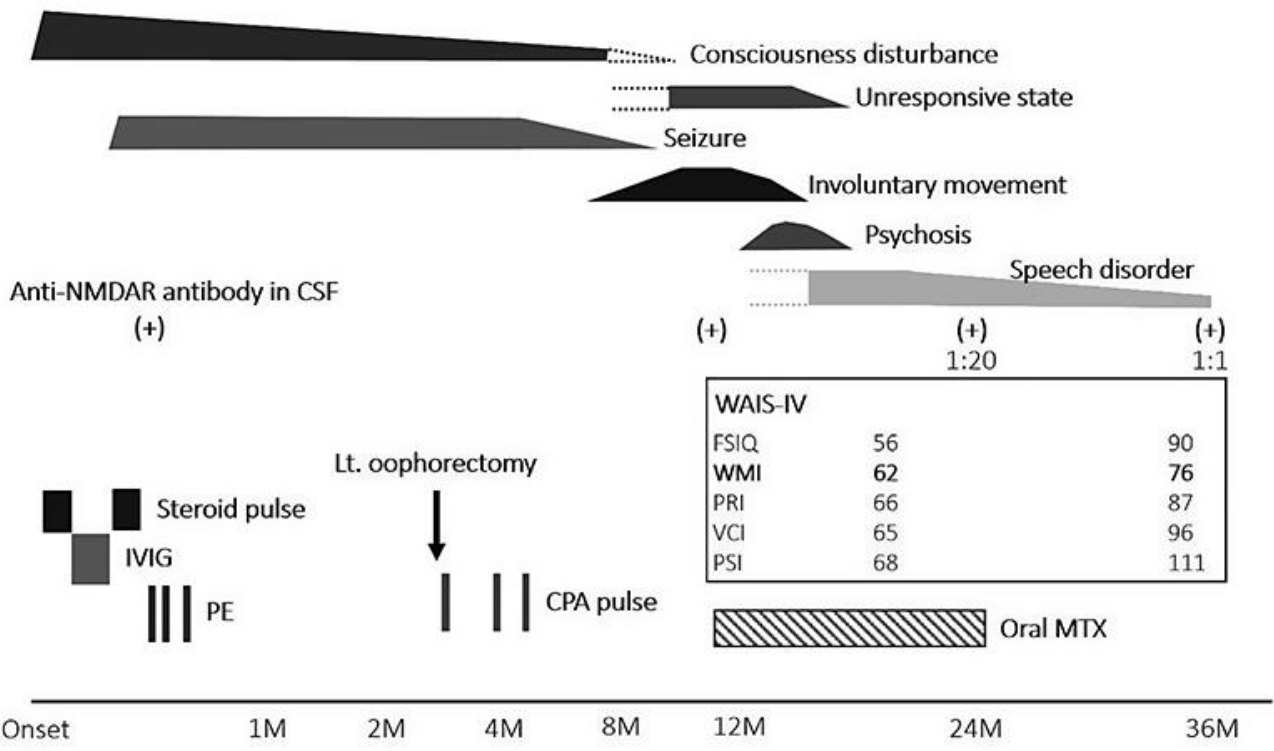

Fig. 1. The clinical course of this case. CPA, cyclophosphamide; CSF, cerebrospinal fluid; FSIQ, full-scale IQ; IVIG, intravenous immunoglobulin; M, month; MTX, methotrexate; NMDAR, N-methyl-D-aspartate receptor; PE, plasmapheresis; PRI, perceptual reasoning index; PSI, processing speed index; VCI, verbal comprehension index; WAIS-IV, Wechsler Adult Intelligence Scale-Fourth Edition; WMI, working memory index. 


\section{Case Reports in Neurology}

\begin{tabular}{l|l}
\hline \multicolumn{2}{l}{ Case Rep Neurol 2021;13:17-23 } \\
\hline DOI: 10.1159/000511026 & $\begin{array}{l}\text { C } 2021 \text { The Author(s). Published by S. Karger AG, Basel } \\
\text { www.karger.com/crn }\end{array}$ \\
\hline
\end{tabular}
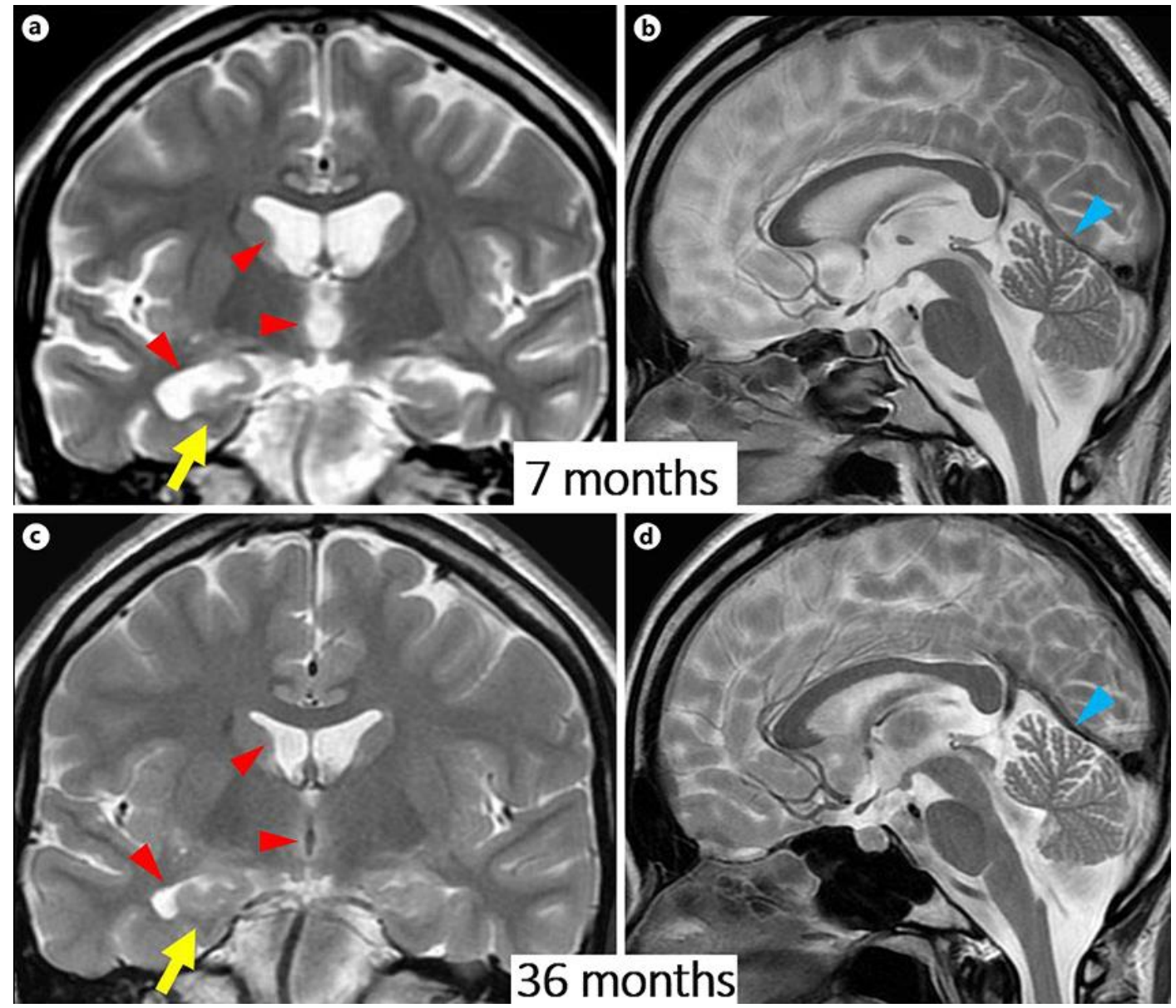

Fig. 2. Brain magnetic resonance imaging findings. a, b T2-weighted images taken at 7 months after onset. a Coronal image shows atrophy of the hippocampus (yellow arrow) and dilation of the lateral and third ventricles (red arrowheads). b Mid-sagittal image shows slight cerebellar atrophy (blue arrowhead). c, d T2-weighted images taken at 36 months after onset. c Coronal image shows reversal of the atrophy of the hippocampus (yellow arrow) and the dilation of the lateral and third ventricles (red arrowheads). $\mathbf{d}$ On mid-sagittal image, the cerebellar atrophy remains but has not progressed (blue arrowhead). 


\section{Case Reports in Neurology}
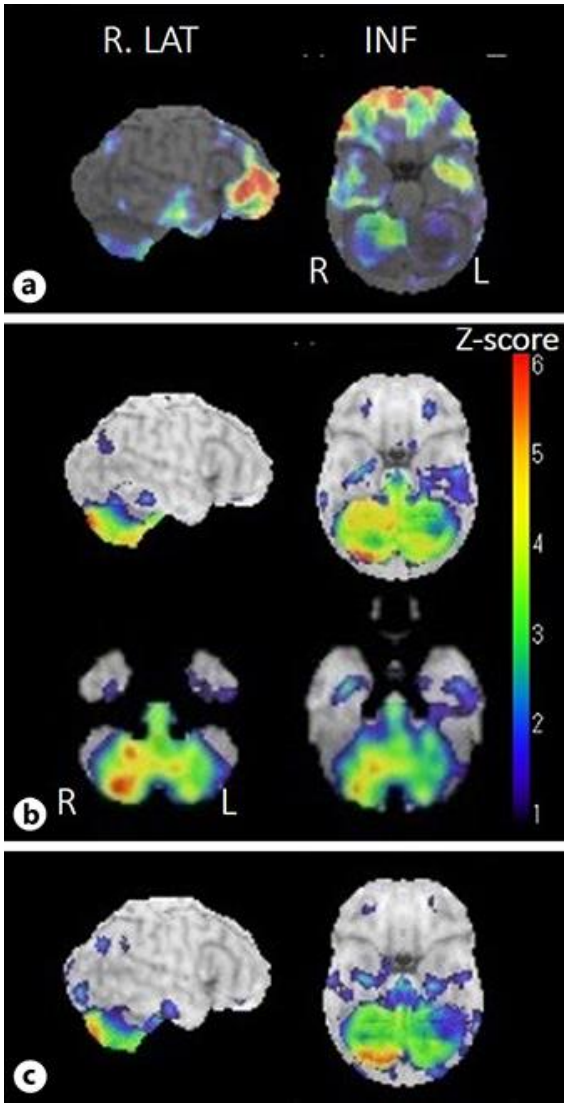

Fig. 3. Sequential findings of cerebral blood flow single-photon emission computed tomography using Nisopropyl-p-[123I] iodoamphetamine. Z-score images using normalized counts of the global brain. The Zscore is higher as the degree of decrease of cerebral blood flow is larger than that of an age-matched normal database. a The image at 7 months after onset shows a decrease in blood flow in the bilateral frontal lobes with slight hypoperfusion in the right anteromedial portion of the cerebellum. $\mathbf{b}$ The image at 24 months after onset shows marked cerebellar hypoperfusion extending bilaterally with right posterior-side predominance, whereas the hypoperfusion of the frontal lobes disappears. The axial images show hypoperfusion in the whole cerebellum including the cortex, white matter, and deep nucleus. c On the image at 36 months after onset, the cerebellar hypoperfusion remains. INF, inferior; L, left; LAT, lateral; R, right. 